\title{
UPDATING HIGH SCHOOL TEACHERS ON GEL ELETROPHORESIS AND RESTRICTION ENZYMES
}

Barbuto, V.S.; Miranda, E.M.; Bossolan, N.R.S.; Oliveira, M.R.G.; Beltramini, L.M.

Centro de Biotecnologia Molecular Estrutural (CEPID/FAPESP) Instituto de Física de São Carlos - USP, São Carlos, SP

The current evolution of the science and technology generated a demand in the teachers' formation that needs constant updating. In that sense, CBME has been elaborating courses and workshops to update teachers of Sciences and Biology involving current themes. The activities on Molecular Biotechnology were elaborated, especially on restriction enzymes and gel electrophoresis. Thirtyseven teachers of public schools participated in the activities. Firstly, it was made an experiment demonstrating the digestion of a plasmidial DNA by two restriction enzymes (Dral and EcoRl), with the subsequent application in gel, in order to elucidate the electrophoresis technique. After the demonstration, simple and practical exercises were distributed to the teachers to simulate those processes using paper ribbons and charts, being concluded with an exercise of a paternity test. A questionnaire was applied as an evaluation tool and from the teachers' answers it was observed, among other data, that $100 \%$ of the teachers classified the activities as interesting, $43 \%$ classified the thematic as actual, $22 \%$ defined it as appropriate to their school reality and $19 \%$ pointed it as a subject on which they have doubts. Also, it was observed that the teachers felt confident dealing with the most specific subjects, when relating it with the daily events and visualizing a possibility of didactic transposition of those themes. 